\title{
EFFECTS OF OUTGASSING FROM SOME MATERIALS ON GAS CHAMBER AGEING
}

\author{
R. Bouclier, M. Capeáns, C. Garabatos, F. Sauli and K. Silander* \\ CERN, Geneva, Switzerland
}

\begin{abstract}
Several different materials that might be used for assembling Micro-strip gas chambers (MSGCs) for high luminosity experiments were tested by measuring the gain of an irradiated wire counter when each sample was put into contact with the gas upstream of the detector. The results show a fast effect on the gain of the counter for some of the materials tested, whereas others, like Stesalit, Vectra, and the epoxy Epotek 505, do not seem to emit dangerous vapours, even at high temperatures.
\end{abstract}

*) Present address: Laboratório de Instrumentação e Física Experimental de Partículas, Coimbra, Portugal. 
Submitted to Nuclear Instruments and Methods in Nuclear Research 


\section{Introduction}

Radiation hardness is an important condition for gaseous detectors expected to operate in high-luminosity collider experiments such as at the Large Hadron Collider (LHC), since they will be exposed to high particle rates for years. For example, the Micro-strip gas chambers (MSGC) designed for this machine are expected to receive, during each year of operation, maximum doses of $0.02 \mathrm{C} / \mathrm{cm}$ of strip.

Amongst the most critical items that affect the lifetime of gaseous detectors are the materials used in the construction of the detector itself, and in the gas station and tubing. This is because many non-metallic materials outgas some vapours which, transported with the gas flow, may be deposited directly on the surface of electrodes and insulators in the chamber, and/or favour the polymerization of radicals in the avalanche plasma, leading to the growth of deposit layers on the irradiated regions. In both cases, the lifetime of the detectors can be seriously shortened. Figure 1 [1] illustrates the dramatic effects of the choice of assembly materials in the gain stability of an MSGC. The rate of the drop in the gain as a function of the absorbed dose on the cathode strips increases by orders of magnitude simply by adding some organic materials in contact with the gas, the rest of the conditions in the irradiation tests being identical.

For obvious reasons (such as the radiation length across the apparatus and the need for electrical insulators) the use of glues, plastics, or organic materials (rigid or flexible) is unavoidable in a practical detector. It is therefore mandatory to test each selected -and otherwise optimal- material for spontaneous, polluting outgassing, even before verifying possible additional outgassing effects caused by the exposure of the sample to ionizing radiation.

Table 1: List of materials tested with some basic properties

\begin{tabular}{|l|c|c|c|c|}
\hline \multicolumn{1}{|c|}{ Material } & Type & $\begin{array}{c}\text { Resistivity } \\
\left(\times 10^{15} \Omega \mathrm{cm}\right)\end{array}$ & $\begin{array}{c}\text { Linear } \\
\text { dilatation coef. } \\
\left(\times 10^{-6} \mathrm{C}^{-1}\right)\end{array}$ & $\begin{array}{c}\text { Density } \\
\left(\mathrm{g} / \mathrm{cm}^{3}\right)\end{array}$ \\
\hline \hline Araldit & & & & 1.2 \\
& AW 106 & & & 0.95 \\
\hline Epotek $^{\mathrm{b})}$ & $\mathrm{E} .505$ & & 64 & 1.1 \\
\hline Duralco $\left.^{\mathrm{c}}\right)$ & 4525 & 1 & 64 & 1.9 \\
\hline Duralco $\left.^{\mathrm{c}}\right)$ & 4461 & 10 & 11.5 & 1.2 \\
\hline Stesalit $\left.^{\mathrm{d}}\right)$ & $4411 \mathrm{~W}$ & 3 & 7 & 1.8 \\
\hline Vectra $^{\mathrm{e})}$ & $\mathrm{C} 150$ & $>5$ & 29 & 1.67 \\
\hline Ryton $^{\mathrm{f}}$ & $\mathrm{R} 4$ & 10 & &
\end{tabular}

a) Produced by CIBA-GEIGY (Switzerland). The epoxy is a modified resin based on Bisphenol $\mathrm{A}$; the hardener is a polyaminoamide modified with a tertiary amine.

b) Produced by ÉPOTECNY Vélizy (France). It is a two-compound epoxy resin. 
c) Produced by Cotronics Corp. (USA). They are two-compound room temperature curing epoxy.

d) Produced by STESALIT AG (Switzerland). It is a synthetic material reinforced with glassfibre.

e) Produced by CELANESE (USA). It is a liquid cristal polymer.

f) Trademark name of PHILIPS Petroleum Co. (USA) for polysulphur phenylene. It is a crystaline aromatic polymer consisting of para-substituted benzene rings connected by a single sulphur ion.

In this paper we present the results of tests for a few epoxies and rigid materials which are suitable for the assembly of gaseous detectors, and in particular for MSGCs. Table 1 summarizes some of their physical properties. In order to test them, each material was introduced into a so-called outgassing box that was arranged in series in the gas inlet line of a single-wire proportional counter [2]. The test consisted of irradiating the proportional counter and periodically monitoring the detector performance (gain, energy resolution) as a function of the charge collected on the anode wire. Eventually, in order to speed up the rate of possible outgassing from a given sample, the outgassing box was heated. This was motivated by the fact that one should try to produce volumes of pollutants outgassed during several years of LHC operation in a few days or weeks. Unfortunately, the scaling factor of this relationship is not known.

\section{Experimental set-up}

Figure 2 shows schematically the stainless steel gas system used to carry out the ageing tests, which has been described elsewhere [3]. The gas mixture flows into the outgassing box (closed with an aluminium flange) where the sample material is introduced, and then enters two identical single-wire proportional counters; the first one is the chamber being tested and is heavily irradiated with an X-ray generator, and the second counter, which receives a moderate dose, is used for correcting the variations of the gain measured in the test chamber caused by ambient changes.

A gas chromatograph (GC) is used for analysing the gas as it flows out of the test chamber. Although the electron capture detector (ECD) used to detect possible impurities in the gas does not identify them unless a specific calibration is performed, it is useful for detecting and monitoring impurities released by the samples.

The ageing tests were usually started by irradiating the test counter for a few days with a collimated X-ray beam (charge rate of a few hundred $\mathrm{nC} \mathrm{cm}^{-1} \mathrm{~s}^{-1}$ ), and by keeping the sample in the outgassing box at room temperature. If the gain of the counter stayed stable during this period of time, the outgassing box was heated up to a temperature of about $50{ }^{\circ} \mathrm{C}$ with the use of a resistive heating ribbon wrapped around it. The test was stopped when either a reasonable amount of charge was collected at the anode with no change in gain, or as soon as any ageing sign was clearly detected.

The gas mixture during all tests was Ar-DME- $\mathrm{H}_{2} \mathrm{O}$ [90-10-0.8]. Previous ageing tests under optimal conditions [3] in the same set-up showed that the addition of some water vapour to the mixture prevents the ageing of the counters. The operating gas gain was $10^{4}$.

\section{Results}

We give below the results of the ageing tests performed with the abovementioned materials. A summary of each test is provided in Table 2. An attempt has 
been made to characterize the rate of ageing with a parameter which does not depend on the particular amount of collected charge in each case. The following expression:

$$
\frac{G}{G_{0}}=a-R^{\prime \prime} \sqrt{Q}
$$

where $a$ is a constant of value $\approx 1$, was phenomenologically found to yield a parameter $R^{\prime \prime}\left[(\mathrm{C} / \mathrm{cm})^{-1 / 2}\right]$ which expresses the variation in the relative gain, $G / G_{o}$, per $1 \mathrm{C} / \mathrm{cm}$ of collected charge with little dependence on the value of $Q$. It should be noted that the rates of ageing measured in these accelerated tests are underestimated, owing to its known dependence on the rate of charge collected at the anode per unit length [3-5].

Table 2: Summary of results of the tests performed

\begin{tabular}{|l|c|c|c|c|c|c|}
\hline Material & $\begin{array}{c}\text { Surface } \\
\left(\mathrm{cm}^{2}\right)\end{array}$ & $\begin{array}{c}\text { Weigh } \\
\mathrm{t} \\
(\mathrm{g})\end{array}$ & $\begin{array}{c}\text { Temperature } \\
\text { of test } \\
\left({ }^{\circ} \mathrm{C}\right)\end{array}$ & $\begin{array}{c}\text { Accumulate } \\
\mathrm{d} \text { charge } \mathrm{a}) \\
(\mathrm{C} / \mathrm{cm})\end{array}$ & $\begin{array}{c}R^{\prime \prime} \\
{\left[(\mathrm{C} / \mathrm{cm})^{-1 / 2}\right]}\end{array}$ & Effect $\mathrm{b})$ \\
\hline \hline Araldit & 176 & 44 & 55 & 0.015 & 0.67 & G.L. \\
\hline Epoxy E.505 & 131 & 3.5 & 50 & 0.164 & 0.038 & N.C. \\
\hline Duralco 4525 & 156 & 4 & 25 & 0.037 & 1.26 & G.L. \\
\hline Duralco 4461 & 156 & 4 & 25 & 0.005 & 0.44 & G.L. \\
\hline Stesalit & 380 & 90 & 75 & 0.240 & 0.047 & N.C. \\
\hline Vectra & 142 & 19 & 50 & 0.249 & $<0$ & N.C. \\
\hline Ryton & 336 & 67 & 50 & 0.107 & 0.21 & G.L. \\
\hline
\end{tabular}

a) Only when the sample was embedded in the gas.

b) G.L. = Gain loss; N.C. = No change.

\subsection{Araldit}

This is a very popular epoxy used extensively in the assembly of frames, wires, etc. of gaseous detectors. The samples used were a few blocks of the mixture Araldit AW 106 with $80 \%$ of HV $953 \mathrm{U}$ hardener, polymerized in an oven at $70^{\circ} \mathrm{C}$ for two days. The ageing test was started keeping the outgassing vessel at room temperature. As shown in Fig. 3, the relative gain in the test chamber (measured from the current drawn by the high voltage power supply) decreases when the vessel is temporarily heated. When $\approx 0.09 \mathrm{C} / \mathrm{cm}$ were collected in the wire the sample was removed from the outgassing box and the gain recovered gently. The ECD showed an extra peak when the sample was in the vessel, with a larger area at higher temperature, indicating the presence of a certain impurity released by this particular epoxy.

\subsection{Epoxy E.505.SI}

This is also a two-component epoxy, which was polymerized at $80^{\circ} \mathrm{C}$ in about 30 minutes. A few glass slides were coated with the sample and introduced into the outgassing box. Figure 4 shows the result of the corresponding ageing test. Even at high temperatures, the gain of the counter does not show significant changes. Indeed, a small peak showed up in the ECD chromatogram when the sample was heated, 
indicating that something was being outgassed (at least at $50^{\circ} \mathrm{C}$ ), but did not affect the performance of the detector.

\subsection{Duralco}

Two types of this epoxy, 4525 and 4461, were tested. Their main characteristic is that they polymerize in air at room temperature, in a few hours. This property would make it possible to assemble detectors with materials having different expansion coefficients (see Table 1), as one could avoid having to heat the assembly. Unfortunately, the results of the gain stability tests, shown in Figs. 5 and 6 for Duralco 4525 and in Fig. 7 for Duralco 4461, are quite negative. As soon as the sample is put in the vessel (shaded areas in the figures), always at room temperature, the gain drops quickly and the energy resolution degrades significantly. Every time the gas was made to flow through the outgassing box after it had been opened to introduce or remove a sample material, the air contained in the box momentarily affected the gain of the proportional counter.

The fast response of the detector gain to the outgassed pollutants suggests that these impurities might stick directly onto the electrode surfaces, thus screening the electric field. At some point, depending on the amount of material coating the electrodes, the detector may or may not recover its original behaviour by, for example, polymerizing these deposits, etching them away with further avalanches, or neutralizing the screening effects by increasing their conductivity, possibly due to the presence of the water in the gas mixture.

\subsection{Stesalit}

Stesalit is a high quality fibreglass used in the construction of frames and support structures for gaseous detectors. A few pieces of this material, previously cleaned with alcohol and baked in the oven at $80^{\circ} \mathrm{C}$, were used as a sample for an ageing test. The result is shown in Fig. 8; no gain drop was noticed even when the vessel is heated at $75^{\circ} \mathrm{C}$ over $0.1 \mathrm{C} / \mathrm{cm}$ accumulated in the anode wire.

\subsection{Vectra}

This is a rigid material that has attractive mechanical and radiation hardness properties [6], and is a good candidate for use as insulating assembly material. In the corresponding ageing test (see Fig. 9), no gain drop was detected in the counter after a long exposure of the sample to the gas at $45-50^{\circ} \mathrm{C}$.

\subsection{Ryton}

This rigid material can be moulded into assembly pieces for gaseous detectors, and is mechanically radiation hard [7]. It has a relatively high thermal expansion coefficient (see Table 1) and is therefore not compatible with epoxies that need to be heated if other materials such as glass are used in the detector assembly. In Fig. 10 the relative gain of the chamber is shown as a function of the collected charge. The gain drops when the sample is in the heated vessel, and recovers when the Ryton is removed from it. Evidence of an impurity associated with the sample was found from the gas analysis made during the ageing test, as indicated in the figure.

\section{Conclusions}


We demonstrated that there are some materials (such as Stesalit, Vectra and the epoxy Epotek E.505) that produce no significant pollutant outgassing even when heated at moderate temperatures, and thus do not affect the lifetime of gaseous detectors. These materials are suited for assembling MSGCs in high-luminosity experiments. No success has been obtained in attempting a combination of materials that may be assembled at room temperature.

\section{Acknowledgements}

The authors would like to acknowledge G. Million and M. Jeanrenaud for their technical support, and A. Breskin, R. D'Alessandro, T. Meyer and V. Pojidaev for kindly providing some of the samples referred to in this work. 


\section{References}

[1] R. Bouclier et al., Ageing studies with micro-strip gas chambers, CERN-PPE/9463 (1994). To be published in Nucl. Instrum. Methods.

[2] A. Acewski et al., RD-10 Proposal, CERN/DRDC/90-40 DRDC/P9 Rev. Nov. 1990.

[3] R. Bouclier et al., Results of wire chamber ageing tests with $\mathrm{CH}_{4}$ - and DME-based gas mixtures, CERN-PPE/94-40 (1994). Nucl. Instrum. Methods A 346 (1994) 114-119.

[4] A. Algeri et al., Some results on HPC ageing with brass and graphite cathodes, CERN-DELPHI/92-103 CAL100 (July 1992).

[5] A.F.J. den Boggende et al., J. Sci. Instrum. Ser. 2, Vol. 2 (1969).

[6] L. Dobrzynski et al., The prism plastic calorimeter: PPC, CERN/DRDC/90-72, DRDC/P18 (1990).

[7] H. Schönbacher and A. Stolarz-Izycka, Compilation of radiation damage test data, CERN 79-08 (1979). 